\title{
FONTES, TEORIAS E MÉTODOS NA ESCRITA HISTÓRICA SOBRE OS PROTESTANTES E PENTECOSTAIS NO ESTADO DO TOCANTINS
}

\author{
Vasni de Almeida ${ }^{1}$
}

\begin{abstract}
Resumo: O conhecimento sobre igrejas evangélicas tradicionais e pentecostais no Brasil, no ano que se comemora os 500 anos da Reforma Protestante, requer incursões em pesquisas que cercam as escritas históricas sobre esse campo religioso, realizadas em várias regiões do país. É com essa intenção que pretendemos apresentar, neste artigo, os estudos sobre igrejas evangélicas tradicionais e pentecostais no Tocantins, estado localizado na Região Norte do Brasil. Consideramos um texto dessa natureza importante no sentido de expor as pluralidades de estratégias e representações religiosas verificadas no campo evangélico brasileiro - um campo ainda muito complexo e lacunar. Partimos da premissa de que é necessário escrever sobre denominações religiosas tomando como ponto de partida os saberes sobre práticas de conquista de fiéis, formação de identidades, normatização de condutas, estruturas de poder, o gênero, entre outros, sempre com o cuidado de se explicitar as fontes e bibliografia utilizadas, bem como os referenciais teóricos assumidos, fazendo emergir daí uma escrita histórica problematizadora.
\end{abstract}

Palavras-chave: Protestantismo; pentecostalismo; sociedade; cultura; religião.

\section{SOURCES, THEORY AND METHODS IN WRITTEN HISTORY ON PROTESTANTS AND PENTECOSTALS IN THE STATE OF TOCANTINS}

\begin{abstract}
The Knowledge of traditional and Pentecostal evangelical churches in Brazil, in the year that celebrates the 500th anniversary of the Protestant Reformation, requires further investigation into the historical writings about this religious field, held in various regions of the country. That's the reason we intend to present, in this article, the studies on traditional and Pentecostal evangelical churches in Tocantins, state located in the Northern Region of Brazil. We consider a text of this nature of utmost importance in the sense of exposing the pluralities of strategies and religious representations verified in the Brazilian evangelical field - a still very complex and dubious field. We start from the premise that it is necessary to write about religious denominations taking as a starting point the knowledge about practices of conquest of the faithful, formation of identities, normatization of conducts, structures of power, gender, among others, always caring about the explicity of sources and used literature as well as the assumed theoretical frameworks, hence giving rise to a problematizing historical writing.
\end{abstract}

Keywords: Protestantism; Pentecostalism; Society; Culture; Religion.

\section{FUENTES, TEORÍAS Y MÉTODOS EN LA ESCRITA HISTÓRICA SOBRE LOS PROTESTANTES Y PENTECOSTALES EN EL ESTADO DE TOCANTINS}

Resumen: El conocimiento sobre iglesias evangélicas tradicionales y pentecostales en Brasil, en el año que se conmemora los 500 años de la Reforma Protestante, requiere incursiones en investigaciones que rodean las escrituras históricas sobre ese campo religioso, realizadas en

\footnotetext{
${ }^{1}$ Doutor em História pela Universidade Estadual Paulista Júlio de Mesquita Filho, Unesp/Assis. Professor Associado do Curso de História da Universidade Federal de Tocantins (UFT), Campus de Porto Nacional. Email: vasnialmeida@uft.edu.br
} 
varias regiones del país. Es con esta intención que pretendemos presentar, en este artículo, los estudios sobre iglesias evangélicas tradicionales y pentecostales en el Tocantins, estado localizado en la Región Norte de Brasil. Consideramos un texto de esa naturaleza importante en el sentido de exponer las pluralidades de estrategias y representaciones religiosas verificadas en el campo evangélico brasileño - un campo aún muy complejo y lacunar. En la premisa de que es necesario escribir sobre denominaciones religiosas tomando como punto de partida los saberes sobre prácticas de conquista de fieles, formación de identidades, normatización de conductas, estructuras de poder, el género, entre otros, siempre con el cuidado de explicitar las fuentes y bibliografía utilizadas, así como los referentes teóricos asumidos, haciendo emerger de ahí una escritura histórica problematizadora.

Palabras clave: Protestantismo; pentecostalismo; sociedad; cultura; religion.

\section{CONSIDERAÇÕES INICIAIS}

Os protestantes se instalaram definitivamente no Brasil a partir de 1850. Até essa década, estavam mais ocupados em prestar serviços religiosos aos imigrantes alemães e ingleses, por meio de atividades de luteranos e anglicanos e de algumas tentativas isoladas e efêmeras de fixação de missionários ingleses e norte-americanos. De 1850 até $1882^{2}$, congregacionais, presbiterianos, metodistas e batistas passaram se fixar em território brasileiro. Missionários e missionárias, principalmente dos Estados Unidos e Inglaterra, organizaram igrejas, escolas dominicais e escolas seculares. Para melhorar a comunicação entre os fiéis conquistados, bem como para dialogar com as instituições sociais brasileiras, fundaram jornais, revistas e publicaram livros que narravam memórias e criavam discursos que os representavam ante uma sociedade que estranhava aquela religiosidade austera.

O pentecostalismo brasileiro, herdeiro do movimento pentecostal norte-americano iniciado no interior de igrejas protestantes, em 1906, foi implantado no Brasil por meio da organização das igrejas Congregação Cristã do Brasil e Assembleia de Deus ${ }^{3}$. pentecostalismo brasileiro contemporâneo é composto por dezenas de igrejas, entre as quais figuram, entre tantas outras, a Igreja Evangélica Pentecostal "Brasil Para Cristo", fundada

\footnotetext{
${ }^{2}$ Os congregacionais organizaram sua primeira igreja no Rio de Janeiro, em 1858, por meio de Robert Kalley. Em 1862, Ashbel Green Simonton, também no Rio de Janeiro, organizou a primeira Igreja Presbiteriana. Em 1871 foi a vez a do missionário Justos Eastham Newman organizar a Igreja Metodista, em Santa Bárbara do Oeste, no interior paulista. Em 1882, Willian Buck Bagby e Annne Luther Bagby fundaram a primeira Igreja Batista, em Salvador, BA.

${ }^{3}$ A Igreja Congregação Cristã no Brasil foi fundada no estado do Paraná, em 1910, por Luigi Francescon, um protestante italiano que migrou para os Estados Unidos em 1890, filiando-se à Igreja Presbiteriana de Chicago. A primeira Igreja Assembleia de Deus, no Brasil, foi fundada por Daniel Berg e Gunnar Vingren, no estado do Pará, em 1911. Ambos eram suecos e convertidos à Igreja Batista da Suécia.
} 
pelo missionário Manoel de Melo, ex-membro da Igreja Assembleia de Deus, em 1956, e a Igreja do Evangelho Quadrangular foi fundada por Harold Willians, em 1951.

O conhecimento sobre igrejas do protestantismo tradicional e pentecostal no Brasil, mormente quando se comemora os 500 anos da Reforma Protestante, requer incursões em pesquisas que cercam as escritas históricas sobre esse campo, realizadas em várias regiões do país. É com essa intenção que pretendemos apresentar, neste artigo, os estudos sobre protestantes e pentecostais no Tocantins, estado localizado na Região Norte. Consideramos um texto dessa natureza importante no sentido de expor as pluralidades de estratégias e representações religiosas verificadas no campo evangélico brasileiro - um campo muito complexo e lacunar, que não se restringe às narrativas produzidas nas regiões Centro-Sul e Sudeste do País.

Partimos da premissa de que é necessário escrever sobre denominações religiosas tomando como ponto de partida os saberes sobre práticas de conquistas de fiéis, formação de identidades, normatização de condutas, estruturas de poder, entre outros, sempre com o cuidado para com os manuseios das fontes utilizadas, com a bibliografia e com os referenciais teóricos assumidos, fazendo emergir daí uma escrita histórica problematizadora.

Para explorar a presença de protestantes e pentecostais no estado do Tocantins, tendo em mira a premissa acima, apresentamos um esboço das bibliografias que têm sustentado os estudos sobre os protestantes e pentecostais no Brasil. Em seguida, apontamos os referenciais teóricos recorrentes em pesquisas dessa natureza e, finalmente, indicamos alguns estudos sobre as igrejas presbiterianas, batistas e assembleianas no norte tocantinense, momento em que apontamos a influência de obras consagradas pela historiografia sobre o protestantismo e pentecostalismo nesses estudos, bem como dos referencias teóricos mais evidentes nesse tipo de escrita.

\section{OS ESCRITOS SOBRE OS EVANGÉLICOS TRADICIONAIS E PENTECOSTAIS BRASILEIROS}

A narrativa dos missionários sobre eles mesmos disponibilizam uma primeira natureza de escritos a compor os estudos sobre o protestantismo e pentecostalismo brasileiro. São obras publicadas com a intenção de tecer os alicerces considerados necessários às instituições religiosas recém instaladas no Brasil. Buscam definir o passado das igrejas enaltecendo práticas de conquistas e projetando um futuro de glória. Inscritas como obras apologéticas, resultam de textos produzidos para registrar eventos, datas significativas, 
polêmicas internas e externas, cisões, entre outros. Para Santos (2006), esses escritos tinham por meta "registrar a vida eclesiástica", produzindo "documentos e fontes fundantes". Para o autor, são obras marcadas pela polêmica, cujo objetivo seria "a defesa da fé reformada no campo religioso". Tencionavam "legitimar o protestantismo na sociedade, valendo-se da expansão do mercado editorial e do aumento de leitores, sobretudo no contexto urbano". Fazem parte desse conjunto de escritos, os livros Cinquenta anos do metodismo no Brasil, (KENNEDY, 1928); Annaes da $1^{a}$ Egreja Presbyteriana de São Paulo, (LESSA, 1938); Magno problema, (AMARAL, 1934); História dos Batistas do Brasil até o ano de 1906, (CRABTREE, 1937) e História das perseguições religiosas no Brasil (TARSIER, 1936).

Outra categoria de escritos apologéticos é composta por obras que procuram relacionar os protestantes e suas relações com a sociedade. Foram escritas principalmente entre 1950 e 1980, e inovam em relação aos textos produzidos por missionários e pastores porque partem dos problemas internos das igrejas e indicam abordagens a partir do chão nacional, ou seja, questões internas nas quais se envolviam as lideranças das igrejas e seus grandes embates. Segundo Santos (2006), trata-se de obras de "cunho mais investigativo, introduzindo a perspectiva do protestantismo como movimento sujeito aos condicionamentos sociais e culturais". No centro das preocupações de tais obras está a tentativa de "mostrar os elementos e os traços trazidos pelo protestantismo à cultura brasileira". (SANTOS, 2006, p. 216). Entre essas obras figuram História da Igreja Presbiteriana no Brasil, (FERREIRA, 1959); Protestantismo no Brasil monárquico e Protestantismo e cultura brasileira, (RIBEIRO, 1973,1981); O protestantismo, a maçonaria e a Questão Religiosa no Brasil, (VIEIRA, 1980) e História do metodismo no Brasil, (SALVADOR, 1982). Mesmo consideradas ainda apologéticas, nem por isso deixam de figurar em dissertações e teses, não apenas como fonte de pesquisa, mas como referencial teórico para se pensar o próprio protestantismo.

O segundo conjunto de escritos sobre o protestantismo brasileiro pode ser chamado de "intérpretes", dado ao avanço metodológico que impôs às pesquisas na área. É composto por obras como $O$ protestantismo brasileiro: um estudo de eclesiologia e história social, de Émile G. Leonard (1963); Católicos, protestantes, espíritas, (CAMARGO, 1973); Protestantismo e repressão, (ALVES, 1982); O celeste porvir - a inserção do protestantismo no Brasil, (MENDONÇA, 1984) e História documental do protestantismo no Brasil, (REILY, 1993). Essas obras inovaram os estudos sobre protestantes e pentecostais no Brasil ao possibilitarem interpretações que fogem dos aspectos eclesiásticos e de fixação de 
identidades. São obras que lançaram mão de abordagens histórico-sociológicas, sem a fragmentação que marcaram os escritos apologéticos. Escritas nas perspectivas sociais, políticas e culturais, interligaram saberes sociológicos, antropológicos, psicológicos e históricos na busca de instituir uma compreensão da cultura protestante no país. Como base teórica para as reflexões que propunham sobre protestantismo, sociedade, cultura e moralidade utilizaram, via de regra, os aportes conceituais de Durkheim (2000), Weber (1992) e Bourdieu (2006, 2009), com algumas pinceladas do marxismo gramnsciniano.

Os estudos sobre os protestantes e pentecostais no Brasil, passaram por mudanças significativas nas décadas de 1990, muito em decorrência dos esforços de pesquisadores preocupados em analisar suas temáticas à luz de metodologias próprias do campo da História, isso sem abrir mão da interdisciplinaridade. Influenciados pelas possibilidades oferecidas pela História Social e pela Nova História Cultural, ou seja, a utilização de categorias analíticas como representação, mentalidade, memória, minorias, cultura, historiadores e historiadoras ampliam em muito as possibilidades de novas compreensões sobre os protestantes no Brasil. A partir da incursão em textos de Certeau, Foucault (1979), Thompson (1987), Ginsburg (2005), Burke (1992) e Chartier (1990), um emaranhado de novas interpretações foi surgindo, promovendo uma leitura a partir de temas como as lutas políticas e sociais, gênero, iconografias, ecumenismo, pluralismo religioso, movimentos sociais, educação escolar, entre tantos outros que ainda não tinham chegado às academias. Inscrevem-se nesse conjunto as teses de doutoramento de Silva (1998), Almeida (2003), Santos (2005), Belloti (2007), Watanabe (2011), e mais recentemente a obra Fiel é a Palavra: leituras históricas e historiográficas do protestantismo brasileiro (SILVA; SANTOS; ALMEIDA, 2011), entre outras.

Para esses pesquisadores, as obras produzidas por teólogos, pastores e missionários, ao se ocuparem em demasia com o jogo de poder estabelecido nas altas hierarquias das igrejas acabaram por privilegiar as vozes dos que se locomoveram nas teias desse poder, em detrimento dos pontos de vista opostos, das crenças não permitidas e das práticas religiosas que afetam doutrinas. Mesmo os estudos elaborados a partir dos fundamentos teóricos do marxismo não conseguem ir muito além das disputas políticas e ideológicas.

\footnotetext{
4 Um conceito muito utilizado nos novos estudos sobre o protestantismo brasileiro é o de "operação historiográfica', de Michel de Certeau, no qual os estudos historiográficos resultam de uma "operação' que envolve três componentes: o seu local social, o conjunto de práticas que o historiador adota; e, por fim, a construção de um texto". (WATANABE, 2010, p. 19).
} 
Essa nova perspectiva de escrita da História apresenta alternativas aos paradigmas tradicional e estrutural, possibilitando estudos das práticas cotidianas, constituídas historicamente. Para tanto, prioriza fontes que não se limitam às decisões eclesiásticas, mas aquelas que delimitam os labirintos dos discursos, as representações dos silenciados, as apropriações dos fundamentos doutrinários. Lentamente, esse tipo de abordagem foi se constituindo pelas mãos de historiadores que não se acanham com a interdisciplinaridade. A inovação desses escritos reside na introdução da crítica histórica na elaboração de métodos, temporalidades e conceitos.

\section{OS REFERENCIAIS TEÓRICOS RECORRENTES}

Os estudos sobre religião no Brasil, há décadas, têm buscado sustentação no conceito de campo de Bourdieu (2005) e no de crença religiosa como cultura, de Geertz (1989). Para Bourdieu, é no interior dos campos, seja ele político, social ou religioso que estão as tensões, lutas e diferentes formas de legitimações de poderes, tendo em vista a constituição de grupos específicos. As pesquisas sobre igrejas protestantes e pentecostais tendem a orientar-se, não poucas vezes, pela noção de habitus religioso, segundo Bourdieu, um

[...] princípio gerador de todos os pensamentos, percepções e ações, segundo as normas de uma representação religiosa do mundo natural e sobrenatural, ou seja, obviamente ajustados aos princípios de uma visão política do mundo social. (BOURDIEU, 2005, p. 57).

Geertz esteve, durante anos, entre os referencias de estudos sobre igrejas evangélicas brasileiras, notadamente devido sua compreensão de crença religiosa como cultura. Ao se ater aos significados dos conceitos religiosos para a vida social, o autor lembra que as crenças religiosas devem ser compreendidas a partir, não somente do que elas significam como conjuntos de normas a inculcar, mas das reações e motivações que elas provocam em quem as praticam. Para o autor, as crenças

[...] não são meras intérpretes dos processos social e psicológico em termos cósmicos - e neste caso seriam filosóficos, não religiosos - mas também as modelam. Na doutrina do pecado original também está embutida uma atitude recomendada em relação à vida, uma disposição periódica e um conjunto persistente de motivações. (GEERTZ, 1989, p. 90).

Outras categorias de análises auxiliaram, principalmente nas décadas de 1970 e 1980, as pesquisas sobre os protestantes e pentecostais brasileiros, a começar por Weber e o debate 
que esse propõe acerca do papel nas doutrinas nos estudos sobre religião. Conquanto as doutrinas não estejam no centro das atenções dos escritos de Weber, ele não ignorava que, de uma forma ou de outra, elas permeiam as práticas sociais de grupos religiosos. Se a doutrina em si não representa uma influência significativa e direta na conduta dos agentes religiosos, seus desdobramentos psicológicos e sociais formam pessoas e criam símbolos que incidem sobre os comportamentos. Afirma que "ação social" desencadeada por diferentes atores sociais é permeada por expectativas oriundas de "objetos exteriores e das ações de outros homens", expectativas essas que agem como um estímulo para se alcançar determinados fins. Além dessa "racionalidade" na "ação social", o autor chama a atenção para os valores religiosos que moldam as condutas dos fiéis. (WEBER, 1978, p. 141).

Nos textos em que esse sociólogo procurou desenvolver análises sobre a questão religiosa, evidencia-se a sua não pretensão em esmiuçar as doutrinas religiosas para a compreensão das práticas das igrejas que estudou. Ele estava mais preocupado numa "história universal da cultura", entendida como práticas econômicas, políticas, educacionais, religiosas e morais. Em Weber, percebe-se todo um cuidado em reunir elementos gerais que configuram os grupos religiosos para, a partir desse ponto, empreender considerações específicas sobre um ou outro grupo, realizando as devidas conexões da religiosidade com a economia, com a política e com a educação. Todavia, o autor destacava que a finalidade de seus estudos não era a lógica das doutrinas das igrejas e seitas. Na primeira nota do seu mais famoso ensaio, deixou bem claro que "o que é valioso numa religião, para o teólogo, não pode desempenhar um papel muito importante nesse estudo" (WEBER, 1992, p. 134). Para Weber, os "resultados práticos" traduzem-se no comportamento social dos protestantes, suas concepções sobre o trabalho, riqueza, educação e outras formas de poder.

Um aprofundamento nas doutrinas e nos dogmas das igrejas protestantes não seria de grande valor para a compreensão da cultura econômica e política sobre a qual Weber se debruçava. Ainda que os princípios doutrinários sejam importantes para distinguir determinadas práticas, Weber não considerava necessário estudar os dogmas para a visualização das condutas dos fiéis. Os referenciais teóricos weberianos indicam, portanto, ser necessário estudar primeiro os comportamentos sociais e, a partir deles, compreender o leque de influências que se tecem no conjunto dos princípios religiosos. No limite, são as práticas culturais que revelam a ingerência das doutrinas nos comportamentos dos agentes religiosos. Ainda que procurasse amenizar o papel dos estudos doutrinários em suas tentativas de 
compreensão das práticas sociais de agentes religiosos, Weber não centralizava, em demasia, seus estudos nos aspectos econômicos da vida em sociedade.

As práticas culturais a que se refere Weber podem ser compreendidas a partir de conceitos diversos, tais como o sentido do dever, a dignidade, a beleza, a sabedoria religiosa, a piedade religiosa. Sendo assim, o que é ético, estético e as formas preferidas para o relacionamento com o ser divino podem ser referências para a organização institucional e cultural de um grupo ligado a uma determinada religião. Nesse sentido, não é a doutrina que indica a prática, mas o conjunto de valores que dela emerge que indica os comportamentos sociais a serem instituídos, não sendo essa uma regra geral, com bem afirma Weber.

Em A ética do protestantismo e o espírito do capitalismo, (1992) estudo no qual se ocupou, entre tantos aspectos, com a conexão protestantismo/capitalismo, foi enfático em destacar o tipo ideal como antagônico aos métodos que se propunham a procurar "nos fatos isolados" o sentido verdadeiro da realidade histórica. De forma deliberada, o autor adotava o ideal como uma possibilidade de problematizar o que era considerado real, em nome da compreensão da cultura das práticas sociais, em certa medida, os tipos ideais.

Segundo essa compreensão, a realidade histórica é permeada por contradições que dificultam a compreensão de seus significados culturais, daí a estratégia de idealizar uma determinada realidade para depois estudá-la passo a passo. Podemos compreender o tipo ideal weberiano ao se investigar uma determinada instituição social, reunindo num mesmo quadro pontos de vista equivalentes, princípios homogêneos e valores identitários, impossíveis de se perceber na realidade concreta. Ainda que existam nessa representação ideias díspares, os tipos ideais possibilitam construir uma unidade, ou o ideal de cultura a ser estudado. Partindo desse princípio, somente após a elaboração do quadro geral é que os pesquisadores podem passar a investigar os casos específicos, sem a pretensão de fazer com que o objeto pesquisado comprove o que foi idealizado. Como bem afirma Weber, o tipo ideal não é o fim, mas o meio para detectar elementos sombreados que somente se evidenciam nas práticas culturais específicas.

O tipo ideal, ainda que necessite de uma representação geral, é um conceito que orienta para o que é particularizado, possibilitando efetuar empiricamente um estudo comparativo. As representações das igrejas, escolas, dos organismos ecumênicos, das associações filantrópicas podem ser o indicador das abordagens teóricas. A finalidade do tipo ideal é possibilidade de se alcançar o específico, no qual, por certo emergirão aspectos culturais renegados por abordagens deterministas, pois o tipo ideal "consiste sempre em tomar 
rigorosamente consciência não do que é genérico, mas, muito pelo contrário, do que é específico a fenômenos culturais". (Idem, p. 145). Questões como racionalidade religiosa protestante, vocação para o trabalho, ética protestante, caráter racional da conduta, ascese cristã, padronização estética, conquista de bens materiais, modernidade e religiosidade, controle de comportamentos, indiferença política são os legados de Weber para os estudos envolvendo protestantes e pentecostais.

As narrativas históricas envolvendo os protestantes e pentecostais no Brasil costumam levar em consideração também o alerta Durkheim, quando esse afirma que o estudo das religiões, como qualquer outro ramo da ciência, não pode ser abordado "pelo simples prazer de contar suas extravagâncias e singularidades”, porém, ele deve estar voltado para a explicação da realidade. As religiões não sobrevivem, obviamente, enclausuradas em suas particularidades, nem foram constituídas para existirem somente para seus pares, ainda mais em se tratando de religiões organizadas enquanto igrejas. Sendo assim, não se restringem às práticas relacionadas ao sagrado, mas existem para explicar e dar sentido a uma determinada realidade. Ao se ater às categorias de entendimento para a compreensão do fenômeno religioso, o autor destacou o papel coletivo e social que as religiões representam. (DURKHEIM, 2000, p. 16).

Os recentes estudos acerca de protestantes e pentecostais brasileiros têm buscado suporte teóricos e metodológicos em autores que assumem a representação como mais uma possibilidade de análise de temas ligados às religiões. Enquanto representações coletivas, as instituições religiosas são formadas por associações de sentimentos e ideias acumuladas na busca do saber. Essas ideias combinadas podem ser tanto a garantia da sobrevivência da religião quanto um fator de convencimento aos propósitos contidos na sua missão. As igrejas são instituições sociais porque elas manifestam as regularidades sociais, portanto, elas não se definem somente em função de "deuses ou de espíritos", mas de uma união de interesses sociais e de rituais sagrados ou sistemas de crenças. Mais precisamente, as religiões são "representações que exprimem a natureza das coisas sagradas e as relações que elas mantêm, seja entre si, seja com as coisas profanas". (DURKHEIM, 2000, p. 22-23).

Há ainda autores que defendem a necessidade de se verificar na religião a constante busca de sentido para a realidade. Bastide (1990) entende a religião como um sentimento de vida, uma constante procura do ser humano, mesmo o contemporâneo, de ingressar no domínio do sagrado. Dupront afirma que a religião, apesar da tentativa de o "espírito moderno" em separá-la de outras formas de existência, permanece como uma necessidade 
para o equilíbrio humano, exprimindo o ser humano em sua totalidade. A religião é, entre as muitas expressões da sociedade, a mais estável, o que possibilita apreendê-la num longo período. Na experiência religiosa o ser humano "vive num ritmo lento e, se for possível compreendê-lo em movimento, podemos decifrar em suas "confissões e testemunhos" o sentido de seu combate em existir”. (DUPRONT,1976, p. 84).

Levando em consideração que as igrejas protestantes e pentecostais são dotadas de princípios religiosos específicos, há que se ter a clareza de que princípios e doutrinas religiosas devem passar pelo crivo da análise histórica produzida pelo pesquisador, já que as crenças religiosas tendem a ser multifacetadas ou a agregar simbolismos antagônicos mesmo no interior das próprias instituições religiosas. Nesse sentido, Julia (1974) alerta que o que interessa ao analista da história religiosa não é a sua condição de verdade, mas o enunciado de verdade religiosa nas relações das religiões com as sociedades abrangentes. Mais do que estudar os domínios eclesiais é necessário interrogar sobre o sentido da religiosidade na constituição social de um grupo e a sua relação com os outros. Faz-se necessário analisar as práticas de uma religião no seu espaço sociocultural preciso, medindo as diferenças com relação aos discursos que as precederam. (JULIA, 1974, p. 108-110). O cânon doutrinário e teológico de uma instituição religiosa é um inegável instrumento para a compreensão de denominações religiosas, mas aos seus princípios fundantes devem ser agregados outros valores religiosos e morais erigidos na conjuntura social e cultural onde estão inseridas as igrejas e grupos.

Os estudos sobre protestantismo e pentecostalismos passaram por mudanças significativas nos últimos anos, em grande medida devido às iniciativas de pesquisas que contam com os referenciais teóricos de historiadores que se desviaram das narrativas dos acontecimentos políticos e das estruturas econômicas, adotando as manifestações culturais em suas interpretações, sejam elas na esfera social, do cotidiano ou das mentalidades. Em pesquisas recentes sobre o campo evangélico brasileiro ficam evidentes que bastam mais as histórias institucionais. Tais historiadores se negam, ainda, a colarem seus objetos às mudanças econômicas, políticas e sociais ocorridas ao nível das estruturas. Mesmo que tardiamente, os estudos recentes sobre os protestantismos e pentecostalismos brasileiro colocaram suas pesquisas nos limites do embate entre os paradigmas tradicionais e os postulados da História Cultural, que no dizer de Burke (1992), uma história que se interessa pela atividade humana em sua totalidade, pelas as mudanças sociais de longo prazo e com a história "vista de baixo". De acordo com esse autor, a História Cultural é inovadora, mesmo 
com todas as suas variações e problemas, por permitir ao historiador o uso de fontes que vão além dos documentos escritos, tais como as visuais, as orais e as estatísticas. (BURKE, 1992, p. 11-16).

Tais possibilidades de escrever a história dos protestantismos e pentecostalismos brasileiros foi abrindo sendas que permitem abordagens voltadas para as apropriações dos discursos, das linguagens visuais, dos gestos e do corpo, do gênero, incorporando em seus eixos de análise aquilo que Hunt (2001) chama de desvio da explicação narrativa e superestrutural para a cultural, essa última compreendida como a valorização de todo o conjunto de experiências materiais e mentais.

\section{PROTESTANTES E PENTECOSTAIS NO TOCANTINS 5}

Os estudos sobre o protestantismo e pentecostalismo brasileiro podem ser realizados por meio de suas doutrinas básicas, das interpretações que clérigos e leigos fizeram das sociedades que acolhem igrejas e escolas, das formas de identificação das igrejas e da visão de mundo de clérigos e leigos sobre temas como política, moralidade, ética, relações de poder e de gênero. Tais temas podem ser verificados na leitura atenta de livros escritos por memorialistas pertencentes às próprias igrejas, nas atas de reuniões, nos boletins internos e nas revistas de catequese.

Os livros de memória descrevem sentidos, significados e expressam identidades. Todavia, devemos lembrar da necessidade de se levar em consideração que suas narrativas são impregnadas dos princípios religiosos caros aos seus emissores. É necessário todo um cuidado em não tomar esses textos como referência teórica, pois muitos fazem apologia da fé que professam. Esses livros devem ser lidos muito mais como fontes de pesquisa.

Nos diferentes tipos de atas disponíveis nas igrejas - como as de reuniões de assembleias paroquiais, de grupos de homens, mulheres, jovens e adolescentes, das associações assistenciais mantidas pelas igrejas, podem sem encontradas informações importantes sobre o cotidiano de seus membros - seus conflitos, sobre as formas de organização de poder, sobre as relações entre homens e mulheres e sobre as estratégias de inserção na sociedade. Nessa documentação emerge uma religiosidade que, muitas vezes, não

\footnotetext{
${ }^{5}$ Estamos tratando especificamente das regiões central e norte desse estado. Em alguns momentos, nos títulos de alguns estudos, aparecerá o termo norte goiano. Isso ocorre porque até 1988, o estado do Tocantins fazia parte do estado de Goiás, uma região mais conhecida como "norte-goiano".
} 
é descrita nos livros dos apologistas. Faz-se necessário, entretanto, estar atento às minúcias, aos detalhes, aos silêncios que estão presentes nesse tipo de fonte.

Além das atas, muitas igrejas protestantes e pentecostais publicam e fazem circular semanalmente os boletins internos. Nesses boletins encontram-se informações relevantes para o pesquisador, como a voz da igreja nas reflexões pastorais em temas políticos e sociais que circulam na mídia impressa e eletrônica, relatórios sobre gastos financeiros, as festas e comemoração de aniversários e dias significativos para as igrejas, horários das atividades religiosas, indícios que podem desvelar uma cultura religiosa não perceptível nos documentos eclesiais.

As revistas de escolas dominicais - o material de catequese das igrejas pentecostais e protestantes, formam outro relevante corpo de documentos a ser utilizado. Até bem recentemente as revistas de catequese ocupavam lugar marginal nas pesquisas sobre os evangélicos. $\mathrm{Na}$ atualidade, um grande número de artigos está sendo escrito tomando como base seus conteúdos. As igrejas protestantes as adotam desde o final do século XIX. Pensadas como recurso pedagógico e didático para o ensino das doutrinas básicas do cristianismo e das respectivas denominações, as revistas de escolas dominicais expressam a mentalidade das igrejas que as publicam. Nas "lições" semanais, pedagogos, pastores, psicólogos, teólogos comentam, à luz de textos bíblicos, temas que circulam nos meios políticos, sociais e culturais, como economia, violência, moralidade, sexualidade, liberdade. Autorizados pelas autoridades das igrejas, os discursos religiosos circulam nas páginas de revistas destinadas aos adultos, jovens, adolescentes e crianças.

Essas fontes, manuseadas com o apoio dos referenciais teóricos que apontamos anteriormente, bem como de uma bibliografia sobre protestantes e pentecostais no Brasil, alicerçaram alguns estudos sobre batistas, presbiterianos e assembleianos no norte tocantinense.

\section{BATISTAS E PRESBITERIANOS}

Com a intenção de estudar as práticas religiosas e assistenciais das mulheres presbiterianas em Araguaína, TO, Nilza Araújo Soares utilizou como fonte de pesquisa as Atas das Sociedade Auxiliadora Feminina - SAF (1966-1980), bem como a Revista SAF em Revista (1999-2001). Com a necessidade de compreender o histórico dos presbiterianos no 
Brasil, a pesquisadora se debruçou sobre as obras de Mendonça $(1984,1990)$ e de Reily (1997).

Para chegar até as práticas assistências das mulheres da igreja, Soares se ocupou da implantação e expansão das atividades religiosas presbiterianas no Brasil, séculos XIX e XX, apontando as ações desencadeadas para o surgimento da Sociedade Auxiliadora Feminina. Elaborou, da mesma forma, o histórico da implantação da Igreja Presbiteriana na cidade, ocorrida em 1965, para, em seguida, descrever a organização da SAF local. Entre os objetivos da SAF, Soares destacou, além da instrução das mulheres, o "cuidar dos pobres e necessitados, visitar enfermos, ajudar no desenvolvimento da igreja e ensinar mães a cuidarem da família e do lar. (2009, p. 10). O assistencialismo é uma das bases do cristianismo protestante e uma das práticas que facilitam sua aceitação na sociedade.

Com a utilização de fontes como a Ata Inaugural da Primeira Igreja Batista de Carolina, MA; as atas de cultos de reuniões da Primeira Igreja Batista de Carolina; Revista Pátria para Cristo e livros de memorialistas que escreveram sobre a presença batista no antigo norte goiano - atual norte do estado do Tocantins, Braga (2012), preocupou-se em mostrar como uma igreja protestante se instala e se desenvolve numa determinada região e estabelece ali seus sistemas de crenças e condutas sociais, com as quais esperam influenciar as sociedades que as acolhe. Para tanto, partiu de referenciais como o de campo religioso e noção de região (BOURDIEU, 2006; 2009) e de moralidade protestante (WEBER, 2004). Para evidenciar o campo religioso batista, descreveu as origens do protestantismo missionário brasileiro e sobre as dificuldades do protestantismo missionário para com o ecumenismo (ALMEIDA, 2010); analisou documentos que serviram de esteio para a narrativa sobre os protestantes no Brasil (REILY, 1993); percorreu a história do protestantes no sul e sudeste do estado do Maranhão (SANTOS, 2006); apresentou as possibilidades de práticas ecumênicas envolvendo os diversos grupos de evangélicos protestantes (SILVA, 2010) e se inteirou da historiografia do protestantismo a partir dos livros escritos sobre essas igrejas (WATANABE, 2011).

Na pesquisa, Braga estudou a implantação da missão batista em Carolina, MA, cidade localizada na fronteira dos estados do Maranhão e Tocantins, considerada a porta de entrada dos evangélicos protestantes no norte goiano, atual norte do estado do Tocantins. Deu destaque para a organização de igrejas e missões batistas entre os indígenas da região e para a implantação do Seminário Teológico Batista na cidade. O eixo de sua análise girou em torno 
das atividades de conversão desencadeadas pelos batistas, consideradas práticas civilizatórias próprias do protestantismo missionário instalado no Brasil na segunda metade do século XIX.

Por meio das narrativas dos memorialistas que escreveram sobre os batistas no sudeste maranhense e norte tocantinense, como as de Oliveira (2007), Braga foi tracejando as origens missionárias dos primeiros pastores e leigos que atuaram em Carolina e cidades vizinhas. Assim, descreveu as ações missionárias de Eurídice de Queiroz, na década de 1940, em cidades como Porto Nacional, Piabanhas, Pedro Afonso, Itacajá, Porto Franco e Babaçulândia. Apontou os esforços de Elcias Câmara para a implantação do Seminário Teológico e do Instituto Batista de Carolina. O primeiro foi organizado para formar pastores para atuarem nas igrejas e o segundo, fundado em 1936, foi pensado para ser um centro de formação de missionárias que atuariam nas áreas educacionais e filantrópicas da região. $\mathrm{Na}$ organização do Instituto, destacou as ações missionárias de Dinalva Sales Queiroz e Lígia Castro. (BRAGA, 2012, p. 35-6). Em sua narrativa histórica, Braga se preocupou em evidenciar as práticas missionárias do pastor batista Zacarias Campelo, tanto nos esforços de fundação de igrejas quanto nas ações entre os indígenas Kraôs.

Silva (2012), estudou a atuação missionária batista entre os índios Xerente do Tocantins. Para apontar para a visão de sociedade contida nas práticas religiosas dessa denominação utilizou livros de memória sobre os batistas, tais como o de Colares (2006) e o de Oliveira (2007). Para destacar as atividades missionárias junto a esses indígenas realizou leituras do Jornal de Missões (2006), da Revista Visão Missionária (2006) e realizou pesquisas no site da Junta de Missões Nacionais. Sua bibliografia de referência para a compreensão da denominação foi composta pelas obras de Gonçalves (2011), Mendonça (1990), Reily (1993) e Silva, Santos e Almeida (2011). Para a compreensão da cultura Xerente, teve como leitura básica a obra de Silva (2010).

Débora Feitosa iniciou sua narrativa sobre os batistas apontando a sua expansão no Brasil a partir da segunda metade do século XIX. Na sequência se debruçou sobre as estratégias de expansão e consolidação dos batistas no Tocantins, indicando Carolina, MA, como o ponto de partida dos missionários que fundaram igrejas, escolas e ações missionários entre os indígenas, a partir da década de 1920. Evidenciou as atividades de Francisco Colares e Beatriz Colares na igreja e na escola batista nessa cidade, bem como as atividades missionárias desenvolvidas entre os índios Kraôs. Teve o cuidado em descrever as escolas fundadas por missionários e missionárias batistas na região. Seu enfoque principal foi narrar o histórico das atividades batistas entre os Xerente, iniciado em 1958, pelo casal Ghunter e 
Wanda Krieger, atividades essas que contaram com o apoio das missionárias Beatriz Silva e Margarida Lemos Gonçalves (SILVA, 2012, p. 18).

Problematizou ainda os materiais utilizados por missionários e missionárias para a atuação junto aos Xerente, tais como cartilhas, hinários, coletâneas de textos bíblicos, todos traduzidos para a linguagem desse grupo indígena, sinalizando para os conflitos que se estabeleceram entre os evangélicos batistas e os agentes da Fundação Nacional do Índio (FUNAI) e pesquisadores da cultura indígena da Universidade Federal do Tocantins. (2012, p. 18-19). Na conclusão de seu estudo escreve:

Ao traduzirem textos bíblicos para a língua indígena, ao organizarem um sistema de educação escolar capaz de formar profissionais para atuarem em escolas, ao realizarem atividades na área de saúde, os batistas não realizaram apenas atividades assistenciais. Eles traduziram e impuseram uma visão de mundo. Estabeleceram princípios e atitudes. Os índios Xerente não foram os mesmos depois de passarem por esse processo educacional, o que nos leva a questionar se na obra missionária batista houve a possibilidade de preservação da cultura indígena. Pesquisas sobre os protestantes que atuam nesse campo precisam se debruçar sobre essa possibilidade. De nosso lado, apenas apontamos o que eles conseguiram realizar". (SILVA, 2012, p. 26).

Lobo (2015), por sua vez, em A mão que embala o berço domina o mundo: práticas educativas das missionárias batistas no antigo norte goiano, voltou-se apenas para as práticas escolares desenvolvidas por missionárias batistas. Para tanto, lançou mão de documentos contidos na Escola Estadual Batista Margarida Lemos Gonçalves, de Araguaína, tais como Projeto Político Pedagógico - PPP, de gravuras pintadas nas paredes da escola, de livros de memorialistas sobre as práticas religiosas e educacionais da missionária Margarida Lemos Gonçalves e demais missionárias da Junta de Missões Batistas. Para desvelar os significados das ações missionárias das mulheres batistas se orientou pelos referencias teóricos de Bourdieu (2009), mais precisamente sobre a formação do campo religioso; de Julia (2001), sobre a cultura escolar; de Hall (2011), sobre o significado do outro na formação identitária e de Orlandi (2005, 2006), sobre a análise do discurso como ferramenta para a compreensão das linguagens educacionais e religiosas das missionárias. No que se refere às questões de gênero, ponto fulcral para se entender as práticas escolares conduzidas por mulheres, a autora se amparou em Scott (1990) e em Butler (2013). Na bibliografia sobre o protestantismo brasileiro figuram as obras de Almeida (2013), Mendonça (1984); Reily (1993) e Silva (1998). 
No desenvolvimento de seu trabalho, Lobo estudou a gênese da denominação batista e sua organização no Brasil, sua implantação no norte goiano e seu envolvimento na educação escolar. Discorreu sobre a organização de sociedades femininas evangélicas para atuação na área educacional, bem como a implantação de escolas batistas por mulheres no Tocantins, destacando as práticas religiosas e escolares de Margarida Lemos Gonçalves como contraponto da educação protestante à cultura religiosa católica instalada na região desde o início do século XX. Havia, segundo Lobo, uma disputa religiosa e nessa disputa se configuravam as identidades de grupos distintos.

Ao se lançarem na educação de crianças e jovens no norte goiano, as missionárias não só ofertavam instrução, ou seja, um agir por impulsos externos, mas também um fortalecimento de seu sistema de crenças. Na ação missionária educacional objetivava-se algo além do ensino tradicional: procurava-se inculcar valores. Ao adotarem essa prática, as missionárias se faziam representar para a sociedade como grupo religioso distinto". (LOBO, 2014, p. 33).

Em 2016, Lobo ampliou o eixo de análise sobre as práticas educacionais femininas batistas, confrontando-as com as propostas educacionais da ordem religiosa dos orionitas, momento em que aprofunda a intensa disputa por territórios religiosos no que, na atualidade, é o norte do Estado do Tocantins. A percepção masculina sobre a atuação feminina das batistas foi devidamente explorada. (LOBO, 2016).

\section{OS ASSEMBLEIANOS}

Livros de memorialistas, como o de Freitas (197?) e entrevistas orais foram as fontes históricas utilizadas por Pereira (2006) para escrever O pentecostalismo em Araguaína: as estratégias de consolidação da Assembleia de Deus do Ministério Serviço de Evangelização Tocantins/Araguaia - SETA. A análise que empreendeu esteve amparada no conceito de crença religiosa, de Geertz (1989) e de moralidade protestante, de Weber (1992). Na busca de demonstrar a formação e expansão do pentecostalismo brasileiro dedicou-se a leitura de Cetrulo Neto (1995) e Freston (1994).

Pereira (2006) foi cuidadoso em apontar a formação do campo protestante na Europa e nos Estados Unidos, indicando a trajetória de organização das igrejas luterana, anglicana, presbiteriana, metodista e batista, bem como o surgimento do pentecostalismo na Europa (séc. XIX) e nos Estados Unidos (séc. XX). Foi minucioso também em descrever a organização dos assembleianos no Brasil, desde as ações dos suecos Daniel Berg e Gunnar Vingren, em Belém 
do Pará, em 1910, com destaque para a aproximação das igrejas Assembleia de Deus, das camadas mais pobres da sociedade. Descreveu a formação das convenções da Assembleia de Deus no Brasil, a partir da década de 1930, quando os assembleianos brasileiros se distanciaram dos missionários suecos Berger e Vingren. Discorreu sobre a formação da Convenção Geral da Assembleia de Deus no Brasil (CGADB), em 1930, e sobre a formação da Convenção Nacional da Assembleia de Deus Madureira (CONAMAD), em 1989. Ao sinalizar para o histórico do Ministério SETA, filiado à CGADB, aponta as ações desencadeadas pelos membros desse ministério para a expansão de igrejas assembleianas na cidade de Araguaína e região, como a entrega de folhetos, cultos nos lares e o assistencialismo. Pereira entende que essa expansão

[...] objetivava não apenas o crescimento da igreja, mas principalmente ocupar lugares vazios que a Igreja Católica não conseguia ocupar. Assim, muitas congregações surgiram em povoados sem uma aparente expressividade, mas que fazendo presença no local, conseguiam fazer valer as pregações e sermões proferidos, aumentando assim o número de fiéis. $\mathrm{O}$ crescimento era uma consequência dessas estratégias de ocupação desses vazios e da evangelização em locais mais difíceis que, geralmente, eram deixados de lado pela Igreja Católica. (PEREIRA, 2006, p. 43).

Os vazios aos quais autor se referia estavam relacionados aos pequenos vilarejos em que houve a construção de igrejas assembleianas, como Pilões, Muricilândia, Babaçulândia, Aragominas, todas no antigo norte goiano. Nessas pequenas cidades, os missionários assembleianos realizavam intensas atividades de conversão junto aos trabalhadores rurais, cozinheiras, pedreiros, enfim, junto às pessoas humildes e pobres. (PEREIRA, 2006, p. 4142).

Para também escrever sobre os assembleianos em Araguaína, Silva (2006), em Batizados nas Águas e no Espírito Santo: inovações da Assembleia de Deus no campo protestante brasileiro, debruçou-se sobre o livro de memória de Cohen (1985) e de Souza (2002). Para compreender os discursos religiosos e suas práticas, se ateve à sociologia religiosa de Berger (1985).

Silva (2006) iniciou seu texto narrando a formação do campo pentecostal no Brasil, desde a chegada dos pastores assembleianos no sudeste do estado do Maranhão, na década de 1920, dando destaque para as ações de Clímaco Bueno Aza. Na sequência, descreveu a organização da Assembleia de Deus no povoado Lontra (futura cidade de Araguaína), em 1947, apontando para as ações religiosas de Israel de Oliveira e João Jonas. Indicou como estratégias de crescimento dos assembleianos em Araguaína, nas décadas de 1950 e 1960, a 
"entrega de panfletos e folhetos, evangelismo pessoal, cruzadas de evangelização, uso de meios de comunicação e cultos na igreja. (SILVA, 2006, p. 48-49).

Com a atenção voltada para a organização, doutrinas e atividades femininas na Assembleia de Deus Madureira, em Araguaína, Coelho (2010), utilizou como fontes de pesquisa o livro de memória Centenário das Assembleias de Deus: temas bíblicos e expositivos, Ápio Junior (2009) e Nossa História: vitórias e conquistas, de Feitosa (2001), bem como os Estatutos da Convenção Nacional da Assembleia de Deus Madureira e a Ata Ministerial da Emancipação da Igreja em Araguaína (1983). Constou em sua análise bibliográfica as obras de Mendonça (2005), Pierucci e Prandi (1996) e de Ramalho (1976).

Coelho (2010) teve o cuidado de estudar as formas de organização da Assembleia de Deus Madureira no Brasil, bem como as práticas religiosas utilizadas para a implantação da igreja em Araguaína. Pesquisou as ações femininas da Confederação de Irmãs Beneficentes Evangélicas (CIBE) e as bases doutrinárias e teológicas justificadoras dos costumes e práticas sociais dos assembleianos do Ministério Madureira. A autora destaca que "um dos valores pregados pela igreja é a simplicidade das pessoas nos modos de vestir, bem como a prudência e a moderação no uso de enfeites e no vestuário, principalmente as mulheres, que eram admoestadas a seguirem os exemplos das mulheres 'santas' da Bíblia". (COELHO, 2010, p. 30). A ideia de que os pentecostais deixaram as normatizações de condutas como marca identitária para suas relações sociais esteve no centro de suas preocupações.

Para descrever o início das atividades religiosas dos assembleianos na cidade de Araguanã, TO, Martins (2013), realizou entrevistas orais com antigos membros da Assembleia de Deus na cidade. Para a interpretação da visão de mundo que emergiram nas narrativas dos entrevistados, o autor lançou mão das considerações sobre o poder religioso (BOURDIEU, 2006). Para deslocar a narrativa dos entrevistados, do campo do discurso religioso para a escrita histórica, buscou apreender os princípios metodológicos propostos por Burke (1992), Le Goff (2003) e por Chartier (2006). Para debater o campo religioso pentecostal no Brasil se amparou nas análises de Belloti (2013), Souza (2011a, 2011b, 2012) e em Watanabe (2006).

Para oferecer uma compreensão sobre os assembleianos na cidade, o autor percorreu a construção do campo religioso pentecostal na Europa (séc. XVIII e XIX), nos Estados Unidos (séc. XX) e no Brasil (séc. XX), relacionando os estudos sobre o pentecostalismo aos avanços possibilitados pela História Cultural. Ao se ater às origens da presença dos assembleianos na cidade de Araguanã, enfatizou os sinais da Teologia da Prosperidade 
verificados nos discursos e atividades religiosas de pastores e leigos. Nas entrevistas realizadas pontuou os significados das ações religiosas do pastor Raimundo Aleluia e sua esposa Cleonice Cardoso Rocha para a implantação de igrejas na cidade. Apontou as estratégias utilizadas para a conquista de novos membros, como evangelização nos espaços públicos, os cultos nos lares e as cruzadas de evangelização. (MARTINS, 2013, p. 29).

Explicou as divisões existentes na Assembleia de Deus, esclarecendo seus inúmeros ministérios e suas respectivas convenções estaduais e nacionais. Deu relevo ao papel secundário reservado às mulheres na igreja, relacionando-o à lógica da cultura patriarcal brasileira. Discutiu a centralidade do poder nas mãos dos líderes masculinos, principalmente dos pastores. Discorreu, com atenção, sobre as recomendações dadas quanto à preservação dos costumes e práticas sociais consideradas corretas pelos assembleianos, tais como as sentenças sobre o uso de vestimentas e de aparelhos de comunicação pelas famílias. (MARTINS, 2013, p. 23-24).

Para escrever A inclusão das instituições religiosas na prevenção da criminalidade na cidade de Araguaína, TO, Arruda (2015), percorreu livros de memórias sobre a Assembleia de Deus no Tocantins, os sermões escritos por pastores para serem utilizados nos cultos em presídios, realizando, ainda entrevistas orais com pessoas ressocializadas a partir das atividades religiosas assembleianas. Para conceituar as práticas religiosas numa unidade prisional, teve como referencial teórico as considerações de Foucault (1987), de Dukkheim (1996) e de Geertz (1989). A bibliografia para narrar o tipo de pentecostalismo que pesquisou se restringiu a História das igrejas Assembleias de Deus no Brasil (ALMEIDA, 1982).

Seguindo os passos de outros estudos sobre os assembleianos no Tocantins, o autor descreveu as origens da Assembleia de Deus no Brasil, sinalizando para as estruturas de poder dessa igreja. Deu especial atenção à organização da Convenção Interestadual da Assembleia de Deus Serviço de Evangelização do Araguaia/Tocantins (CIADSETA), em 1952, posteriormente desmembrado em outros dois ministérios: o SETA e a Convenção das Assembleia de Deus no Estado do Tocantins (CADETINS). Destacou os projetos de ressocialização desenvolvidos pelos religiosos assembleianos na Unidade de Tratamento Prisional de Barra da Grota, no norte do estado do Tocantins, e analisou os sermões escritos e proferidos por pastores nessa unidade prisional, na perspectiva da ressocialização e dos direitos humanos. Para Arruda, as práticas religiosas dos pastores funcionam como estratégias de normatização de comportamentos. 
O discurso religioso, como o praticado pelos pastores assembleianos, rompe com o propósito do sistema prisional, pois a possibilidade de pertença ao grupo dos "salvos" recoloca o preso na vivência social. Aos poucos, pelo apego as esperanças de uma nova vida, a volta à normalidade passa a ser uma meta. Nesse sentido, o discurso religioso faz aquilo que o sistema prisional busca fazer com o aprisionamento: trazer à normalidade os anormais. O discurso religioso não tira o preso da cadeia, pois para isso existe os tramites jurídicos, mas religa a alma do preso ao ser divino, rompida quando da execução do ato infrator. (ARRUDA, 2015, p. 27).

Mais uma vez a ação religiosa como possibilidade de normatizar comportamentos sociais e individuais, fenômeno que perpassa por todo o cristianismo e demais religiões, veio à tona, o que ressalta que o pentecostalismo tem na prática missionária uma forma de intervenção social.

\section{CONSIDERAÇÕES FINAIS}

Os estudos sobre religiões e religiosidades precisam de amparo teórico, pelo menos devem conter reflexões esclarecedoras de conceitos, categorias, nomes e lugares narrados. No caso dos estudos sobre o protestantismo e pentecostalismo no Tocantins, os pesquisadores se defrontam com a dificuldade em encontrar referenciais teóricos próprios da área da História. Isso porque ainda são poucos os estudos históricos e historiográficos sobre o protestantismo e pentecostalismo brasileiro realizados por pesquisadores formados na área, realidade que vem sendo alterada muito lentamente nos últimos anos.

Os referencias teóricos e bibliográficos ainda dependem da produção científica de sociólogos, antropólogos e teólogos que escreveram nas décadas de 1970 e 1980. Cândido Procópio Camargo, Rubem Alves, Antônio Gouvêa de Mendonça, Prócoro Velasques e Duncan Alexander Reily, para ficar somente em alguns, ainda são esteios para esse tipo de estudo. Por sua vez, esses estudiosos foram buscar em teólogos franceses, ingleses e alemães os fundamentos epistemológicos para suas pesquisas, entre eles Paul Tillich, Ernest Troeltsch, Karl Barth. Somente a partir da década de 1990 é que as pesquisas históricas estão se deslocando dessa influência e assumindo as abordagens culturais e sociais dos historiadores franceses, ingleses, latinos e norte-americanos.

As pesquisas aqui apresentadas refletem um pouco a passagem do modelo narrativo sociológico/teológico para o campo histórico e historiográfico, sem negar, porém, a sua natureza interdisciplinar. Da mesma forma que buscam em Pierre Bourdieu, Clifford Geertz, Emile Durkheim e Max Weber as compreensões sobre as relações entre religião e sociedade e 
em Antônio Gouveia de Mendonça e Duncan Alexander Reily as interpretações para a implantação e expansão de protestantes e pentecostais no Brasil, aventuram-se em dialogar com textos de Michel Foucault, Jacques Le Goff, Peter Burke, Michel de Certeau, Judith Butler e Joan Scott.

Desse esforço, as pesquisas aqui descritas trouxeram à baila as práticas de intervenção social de missionários e missionárias, as tentativas de inculcar valores culturais e religiosos naqueles que entravam em contato na região, as estratégias para formar grupos religiosos em um ambiente de forte presença católica, os espaços de atuação das mulheres no interior das igrejas e missões. Na busca de narrar esse cotidiano, abre-se a possibilidade de mais saberes sobre as igrejas reformadas (e seus desdobramentos) no Brasil.

\section{REFERÊNCIAS BIBLIOGRÁFICAS}

ALMEIDA, A. História das Assembleias de Deus no Brasil. Rio de Janeiro: CPAD, 1982.

ALMEIDA, Vasni de. Converter, ensinar e conformar: a missão metodista em Ribeirão Preto (1996-1950). Franca: UNESP, Dissertação de Mestrado em História, 1997.

A educação, a ordem e a civilidade: práticas educativas do metodismo em Ribeirão Preto, Birigui e Lins - 1999/1959. Assis, SP: UNESP, Tese de Doutorado, 2003.

O estabelecimento do Reino de Deus: razões históricas para o antiecumenismo brasileiro. In: MATEDDI, André Luís. História, Cultura e Poder. Salvador: Editora da UFBA, 2010a.

- Os protestantes de origem missionária no Brasil: abordagens recorrentes e possibilidades de interpretações. In: RAMOS, Dernival Venâncio, et.all. (orgs.). Teoria, métodos e abordagens em História. Goiânia: Gráfica e Editora Vieira, 2010b.

Referenciais e fontes em estudos sobre o protestantismo missionário. In: ALMEIDA, Vasni de; VIEIRA, Martha Victor (orgs). Caminhos da História: sugestões para pesquisa no ensino superior. Curitiba: Editora CVR, 2013.

ALVES, Rubem. Protestantismo e repressão. São Paulo: Ática, 1982.

O que é religião. São Paulo: Brasiliense, 1984.

AMARAL, Epaminondas Melo do. Magno problema. Rio de Janeiro: Centro Brasileiro de Publicidade, 1934.

ARRUDA, Dionísio Pereira. A inclusão das instituições religiosas na prevenção da criminalidade na cidade de Araguaína. Araguaína - TO: UFT, Monografia de Conclusão de Curso de Espacialização em Segurança Pública, 2015.

ÁPIO JUNIOR, Raimundo Macedo. Centenário das Assembleias de Deus: temas bíblicos e expositivos. Araguaína, mimeo, (197?).

ATAS DAS SOCIEDADE AUXILIADORA FEMININA - SAF. Araguaína: Arquivo da Igreja Presbiteriana do Brasil. (1966-1980)

BASTIDE, R. Elementos da sociologia religiosa. São Bernardo do Campo: Umesp/Ciências da Religião, 1990. 
BELLOTTI, Karina Kosicki. Delas é o reino dos céus: mídia evangélica infantil na cultura pós-moderna do Brasil - anos 1950-2000. Campinas: UNICAMP, Tese de Doutorado em História, 2007.

História das Religiões: conceitos e debates na era contemporânea, 2013. Disponível em http://ojs.c3sl.ufpr,br/ojs2/index.php/historia/article/view/26526. Acesso em 17/02/2014.

BERGER, P. O dossel sagrado: elementos para uma teoria sociológica da religião. Trad. José Carlos Barcellos. São Paulo: Paulinas, 1985.

BOURDIEU, Pierre. Os usos sociais da ciência. Por uma sociologia clínica do campo científico. São Paulo: Edunesp, 2004.

A economia das trocas simbólicas. $6^{\text {a }}$ edição. São Paulo: Perspectiva, 2005.

. O poder simbólico. Rio de Janeiro: Bertrand Brasil, 2006.

BRAGA, Cristiano Marinho. A missão protestante em Carolina, MA: narrativas de experiências missionárias e de conversão (1926-1975). Araguaína, TO: Monografia de Conclusão de Curso de História, 2012.

BURKE, P. A escrita da História: novas perspectivas. São Paulo: Editora da Unesp, 1992.

BUTLER, Judith P. Problemas de gênero: feminismo e subversão da identidade. $5^{\mathrm{a}}$ Ed. Rio de Janeiro: Civilização Brasileira, 2013.

CAMARGO, Cândido Procópio Ferreira de. Católicos, protestantes, espíritas. Petrópolis, RJ, Vozes, 1973.

CHARTIER, Roger: A história cultural entre práticas e representações; tradução de Maria Manuela Galhardo. -Rio de Janeiro : Bertrand Brasil ; 1990.

A visão do historiador modernista. In: FERREIRA, Marieta de Moraes; AMADO, Janaína (orgs.). Usos e abusos da História Oral. Rio de Janeiro: Editora FGV, 2006.

COELHO, Rejane Gonçalves da Rocha. Unidade na Diversidade: a organização da Assembleia de Deus do Ministério Madureira em Araguaína, TO (1993-2003). Araguaína, TO: UFT. Monografia de Conclusão de Curso de História, 2010.

COHEM, Armando Chaves. Minha vida. Brasília: mimeo, 1985.

COLARES, Samuel Almeida. Meu Pai, apenas um servo. $1^{\text {a }}$ edição. Rio de Janeiro, Confiança, 2006.

CRABTREE, A. R. História dos Batistas do Brasil até o anno de 1906. Rio de Janeiro: Casa Publicadora Baptista, 1937.

DE CERTEAU, M. A escrita da história. Trad. Maria de Lourdes Mensezes, $2^{\mathrm{a}}$ ed. Rio de Janeiro: Forense Universitária, 2006.

DUPRONT, A. A religião: antropologia religiosa. In: LE GOFF, Jacques, NORA, Pierre. História: novas abordagens. Tradução de Henrique Mesquita. Rio de Janeiro, Francisco Alves, 1976.

DURKHEIM, Émile. As Formas Elementares da Vida Religiosa. São Paulo: Livraria Martins Editora Ltda, 1996. As formas elementares da vida religiosa. São Paulo: Paulus, 2000.

FERREIRA, Júlio Andrade. História da Igreja da Igreja Presbiteriana do Brasil em comemoração ao seu primeiro centenário. São Paulo: Casa Editora Presbiteriana, 1959.

FEITOSA, João. Nossa História: vitórias e conquistas. Araguaína, mimeo (198?).

FOUCAULT, Michel. Microfísica do poder. Organização e tradução de Roberto Machado. Rio de Janeiro: Edições Graal, 1979. 
Vigiar e Punir: o nascimento da prisão. Tradução de Raquel Ramalhete. 32 ed. Petrópolis, RJ: Vozes, 1987.

FREITAS, Francisco Bueno de. História da Assembleia de Deus em Araguaína. Araguaína TO, mimeo, [197?]

FRESTON, Paul. Uma breve história do pentecostalismo brasileiro: a Assembleia de Deus. Revista Religião e Sociedade. Rio de Janeiro: ano XVI, p. 104-129, 1994.

GEERTZ, Clifford. A interpretação das culturas. Rio de Janeiro: Livros Técnicos e Científicos Editora, 1989.

GINZBURG, Carlo. O queijo e os vermes: o cotidiano e as ideias de um moleiro perseguido pela Inquisição. São Paulo: Companhia das Letras, 2005.

GONÇALVES, Carlos Barros. Até aos confins da terra: o movimento ecumênico protestante no Brasil e a evangelização dos povos indígenas. Dourados: Ed. UFGD, 2011.

GONÇALVES, Margarida Lemos. A que faz feliz. Publicação da União Geral de Senhoras. Rio de Janeiro: Casa Publicadora Batista, 1962.

HALL, Stuart. A identidade cultural na pós-modernidade. $11^{\mathrm{a}}$ ed. Rio de Janeiro: DP\&A, 2011.

HUNT, L. A nova história cultural. Trad. Jefferson Luís Camargo, 2ª ed. São Paulo: Martins Fontes.

JORNAL DE MISSÕES. Arquivo pessoal de Débora Feitosa. Araguaína, TO. 2006.

JULIA, D. A religião: história religiosa. In: LE GOFF, Jacques, NORA, Pierre. História: novas abordagens. Tradução de Henrique Mesquita. Rio de Janeiro, Francisco Alves, 1974.

JULIÁ, Dominique. A cultura escolar como objeto histórico. Em: Revista Brasileira de história da educação. Campinas, Editores Associados, n. 1, junho-janeiro, 2001.

KENNEDY, James Long. Cinquenta anos de Metodismo no Brasil. São Paulo: Imprensa Metodista, 1928.

LE GOFF, Jacques. História e memória. Campinas: Editora da UNICAMP, 2003.

LEONARD, Émile-G. O protestantismo brasileiro: estudo de eclesiologia e história social. Trad. Linneu de Camargo Schützer. São Paulo: ASTE, 1963.

LESSA, Vicente Themudo. Anaes da $1^{a}$ Egreja Presbyteriana de São Paulo, 1863-1903. São Paulo: Cruzeiro do Sul, 1938.

LOBO, Maíza Pereira Lobo. A mão que embala o berço domina o mundo: práticas educativas das missionárias batistas no antigo norte goiano. Araguaína, TO: UFT, Monografia de Conclusão de Curso de Graduação em História, 2014.

- O sagrado como elemento de territorialização das missionárias batistas no antigo norte goiano. Campina Grande, PB: Mnemosine Revista. Revista da Pós-Graduação em História da UFCG, vol. 7, n. 3, jul/set. 2016.

MARTINS, Lucas. A inserção de uma igreja pentecostal no norte tocantinense: a Assembleia de Deus em Araguanã (1991-2013). Araguaína, TO: UFT. Monografia de Conclusão de Graduação no Curso de História, 2013.

MENDONÇA, A. G. O celeste porvir: a inserção do protestantismo no Brasil. Rio de Janeiro: Paulinas, 1984.

MENDONÇA, Antônio Gouveia de; VELASQUES, Prócoro. Introdução ao protestantismo no Brasil. São Paulo: Loiola, 1990. 
O protestantismo no Brasil e suas encruzilhadas. (http://www.usp.br/revistausp/67/05mendonca.pdf). Acesso em 02/02/2012. Publicação impressa: Revista USP, São Paulo, n.67, p. 48-67, set./nov., 2005.

CETRULO NETO, Francisco. Os que semeiam chorando, ceifarão com júbilo: a origem da Assembleia de Deus em Belém. Belém: Dissertação de Mestrado, UFPA.

OLIVEIRA, Zaqueu Moreira de. Desafios e conquistas missionárias: 100 anos da Junta de Missões Nacionais da CBB. Rio de Janeiro: Convicção Editora, 2007.

ORLANDI, Eni Puccinelli. Análise do discurso: princípios e procedimentos. 6 ed. São Paulo: Fontes: 2005.

A linguagem e seu funcionamento. Campinas: Fontes, 4ª Edição, 2006.

PEREIRA, Jerse Vidal. O pentecostalismo em Araguaína: as estratégias de consolidação da Assembleia de Deus do Ministério SETA. Araguaína, TO: UFT. Monografia de Conclusão de Curso de História, 2006.

PIERUCCI, Antonio Flávio; PRANDI, Reginaldo. A realidade social das religiões no Brasil. São Paulo: Hucitec, 1996.

RAMALHO, Jheter Pereira. Prática educativa e sociedade. Rio de Janeiro: Paz e Terra, 1976. REILY, Ducan Alexander. História Documental do Protestantismo no Brasil. São Paulo: Aste, 1993.

. Ministérios femininos em perspectiva histórica. Campinas, CEBEP; São Bernardo do Campo: EDITEO, 1997.

REVISTA SAF EM REVISTA. Araguaína: Arquivo da Igreja Presbiteriana do Brasil. (19992001).

REVISTA VISÃO MISSIONÁRIA. Araguaína, Arquivo pessoal de Débora Feitosa, 2012.

RIBEIRO, Boanerges. Protestantismo no Brasil monárquico, 1822-1888: aspectos culturais de aceitação do protestantismo no Brasil. São Paulo: Pioneira, 1973.

$O$ protestantismo e cultura brasileira: aspectos culturais da implantação do Protestantismo no Brasil. São Paulo: Casa Editora Presbiteriana, 1981.

SALVADOR, José Gonçalves. História do Metodismo no Brasil. São Paulo: Imprensa Metodista, 1982.

SANTOS, Lyndon de Araújo. As outras faces do sagrado: protestantismo e cultura na Primeira República. Assis, SP: UNESP, Tese de Doutorado, 2005.

As outras faces do sagrado: protestantismo e cultura na primeira República Brasileira. São Luís, MA: Edufma, 2006.

SCOTT, Joan. Gênero: uma categoria útil de análise histórica. In: Educação e realidade. V. 15, n.2, jul/dez. 1990, p.71-99.

SILVA, Cleube Alves da. Confrontando Mundos: Os povos indígenas Akwen e a conquista de Goiás (1749-1851). Palmas: Nagô Editora, 2010.

SILVA, Débora Feitosa da. Os evangélicos batistas no Tocantins: a ação missionária entre os índios Xerente (1958-2010). Araguaína, TO: UFT. Monografia de Conclusão de Curso de História, 2012.

SILVA, Diogo Pereira da. Batizado nas águas e no Espírito Santo: inovações da Assembleia de Deus no campo protestante brasileiro. Araguaína, TO: UFT, Monografia de Conclusão de Curso de Graduação em História, 2006.

SILVA, Elizete da. Cidadãos de outra pátria: anglicanos e batistas na Bahia. São Paulo: USP, Tese de Doutorado em História, 1998. 

2010.

Protestantismo ecumênico e realidade brasileira. Feira de Santana: Editora da UEFS,

SILVA, Elizete da; SANTOS; Lyndon Araújo dos; ALMEIDA, Vasni de. (Orgs.) "Fiel é a Palavra": leituras históricas dos evangélicos protestantes. Feria de Santana: UEFS Editora, 2011.

SOARES, Nilza Araújo. Assistir aos necessitados e redimir os perdidos: as práticas religiosas das mulheres presbiterianas em Araguaína (1966-2006). Araguaína: UFT. Monografia de Conclusão de Curso de Graduação em História, 2009.

SOUSA, Bertone de. Uma perspectiva histórica sobre construções de identidades religiosas: a Assembleia de Deus em Imperatriz, MA. Imperatriz: Editora Ética, 2011 a.

A Teologia da Prosperidade e a redefinição do protestantismo brasileiro: uma abordagem à luz da análise do discurso. Revista Brasileira de História das Religiões ANPUH, ano IV, n. 11, set. 2011b. Disponível em: http://www.dhi.uem.br/gtreligiao/index.html>. Acesso em: 12/11/2013.

. Historiografia do Protestantismo no Brasil: percursos e perspectivas. Revista Mosaico, vol. 5, n. 2, p. 171-179, jul./dez. 2012. Disponível em: http://seer.ucg.br/index.php/mosaico/article/viewfile/2502/1557. Acesso em 12/11/2013.

SOUSA, Sebastião Cleyton Alves de. História da Assembleia de Deus em Imperatriz, MA: Edição comemorativa de Jubileu de Ouro. Imperatriz: IEADI, 2002.

TARSIER, Pedro. História das perseguições religiosas no Brasil. São Paulo: Cultura Moderna, 1936.

THOMPSON, Edward Palmer. A Formação da Classe Operária Inglesa: A Árvore da Liberdade. Rio de Janeiro: Paz e Terra. 1987.

VIEIRA, David Gueiros. O Protestantismo, a Maçonaria e a Questão Religiosa no Brasil. Brasília: Editora Universidade de Brasília, 1980.

VIDAL, Jerse Pereira. O pentecostalismo em Araguaína: as estratégias de consolidação da Assembleia de Deus do Ministério Serviço de Evangelização Tocantins/Araguaia - SETA. Araguaína: UFT, Monografia de Conclusão de Curso de História, 2006.

WATANABE, Thiago Hideo Barbosa. Escritos nas Fronteiras: os Livros de História do Protestantismo Brasileiro. Assis, SP: UNESP, Tese de Doutorado em História, 2010.

A construção da diferença no protestantismo brasileiro. Revista Aulas, n. 4, abr./jul. 2007. Disponível em: http://www.unicamp.br/ aulas/conjunto\%20111/4_22.pdf. Acesso em 10/09/2013.

WEBER, M. Ação social e relação social. In: FORACHI, M. M.; MARTINS, J. S. Sociologia $e$ sociedade: leituras de introdução à sociologia. Rio de Janeiro: Livros Técnicos e Científicos, 1978.

A ética protestante e o espírito do capitalismo. São Paulo: Pioneira, 1992.

A ética protestante e o "espírito do capitalismo". São Paulo: Companhia das Letras, 2004.

Economia e Sociedade: fundamentos da sociologia compreensiva. Brasília: UNB; Imprensa Oficial, 2004.

Recebido em: 02/08/2017

Aprovado em: 16/12/2017 